\title{
Large polyazacycloalkanes: ligational properties and anion coordination chemistry
}

\author{
A. Bianchi, M. Micheloni, P. Paoletti \\ Department of Chemistry, University of Florence \\ Via Maragliano, 75/77, I-50144 Florence (Italy)
}

\begin{abstract}
The synthesis and ligational properties of a series of large polyazacycloalkanes are reviewed. $|3 \cdot k|$ aneN (with $k=7,8,9,10,11,12$ ) is the general formula which can be used to represent the macrocycles investigated. The general synthetic route followed to synthesize these macrocycles is reported. The basicity constants have been determined and discussed in term of charge repulsions and macrocyclic size. The marked tendency to form polynuclear complexes is demonstrated by the numerous and stable polynuclear metal complexes formed. In the case of the largest macrocycles $(k=11,12)$ stable trinuclear species $\left|\mathrm{Cu}_{3} \mathrm{~L}\right|^{6+}$ are formed. For each equilibrium many protonated and hydroxo species are present. For $k=8$ and $k=10$ good crystals of binuclear copper(II) complexes were obtained and X-ray analyses carried out. The second-sphere interaction between the complex anions $\left|\mathrm{Fe}(\mathrm{CN})_{6}\right|^{4-},\left|\mathrm{Co}(\mathrm{CN})_{6}\right|^{3-}$ and the polyprotonated (polycharged) form of the macrocycles have been studied by potentiometry and cyclic voltammetry. A 'supercomplex' was isolated and its structure solved by X-ray.
\end{abstract}

\section{INTRODUCTION}

Many publications on the coordination chemistry of synthetic macrocyclic compounds have been published in recent years (refs. 1-4). Among polyazacycloalkanes the tetraazacycloalkanes are by far the most studied (refs. 5-14). Much less has been instead reported about large polyazacycloalkanes having more than six nitrogen donor atoms (refs. 15-16).

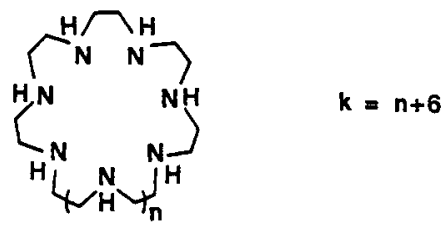

\begin{tabular}{lll}
$|3 \cdot \mathrm{k}|$ aneN & \multicolumn{1}{c}{ name } & abbrev \\
$|21|$ aneN & $1,4,7,10,13,16,19$-Heptaazacycloheneicosane & $\mathrm{L} 7$ \\
$|24|$ aneN $_{8}$ & $1,4,7,10,13,16,19,22$-Octaazacyclotetracosane & $\mathrm{L} 8$ \\
$|27|$ aneN $_{9}$ & $1,4,7,10,13,16,19,22,25$-Nonaazacycloheptacosane & $\mathrm{L} 9$ \\
$|30|$ aneN $_{10}$ & $1,4,7,10,13,16,19,22,25,28$-Decaazacyclotriacontane & $\mathrm{L} 10$ \\
$|33|$ aneN & $1,4,7,10,13,16,19,22,25,28,31$-Undecaazacyclotritriacontane & $\mathrm{L} 11$ \\
$|36|$ aneN & $1,4,7,10,13,16,19,22,25,28,31,34$-Dodecaazacyclohexatriacontane & L12
\end{tabular}

Fig. 1. Drawing of the macrocycles studied with their names and abbreviations hereafter used. 
The possibility for these synthetic macrocycles to bind more than one metal ion in the cyclic framework and the recent development of the anion coordination chemistry (refs. 17-18) have made the investigation of large polyazamacrocycles interesting. We have studied a series of large polyazacycloalkanes having the general formula $|3 \cdot k| a n e N_{k}$ ( with $k=7,8,9,10,11,12)$. In this series all donor atoms, which are secondary nitrogens, are separated by an ethylenic chain. In Fig. 1 the large polyazacycloalkanes studied and their abbreviations, hereafter used, have been reported.

\section{SYNTHESIS}

The synthetic procedure followed for the preparation of each polyazacycloalkane was modeled on the general procedure described by Atkins (ref. 15) for this kind of compounds. It is described in Fig. 2 .
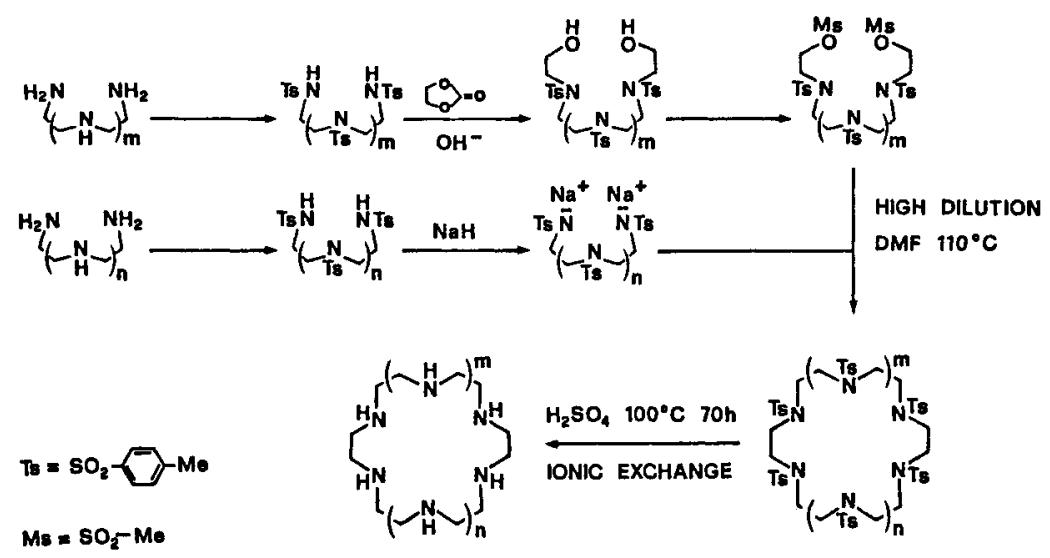

Fig. 2. Reaction scheme for the synthesis of large polyazacycloalkanes.

In this reaction sequence key steps are the elongation of the linear polyamines by ethylene carbonate as well as the cyclization reaction. The overall yield is strongly reduced as the size of the macrocycle increases. The removal of tosyl groups, done with concentrated sulfuric acid, works well in all cases. The final macrocyclic compounds are purified as hydrochloride salts and characterized by standard techniques.

\section{EQUILIBRIUM STUDIES}

The stepwise protonation constants for the macrocycles investigated have been determined at $25{ }^{\circ} \mathrm{C}$ by potentiometry. The basicity constants for the $|3 \cdot \mathrm{k}|$ ane $\mathrm{N}_{\mathrm{k}}$ series are given in Table 1 and the overall basicity constants are plotted in Fig. 3a. The results clearly show that each large azamacrocycle behaves as a relatively strong base in the first half of its protonation steps and as a weaker base in the second half. This grouping of the basicity constants is always present in polyazamacrocycloalkanes (refs. 12,19,20). This behavior has been ascribed to the electrostatic repulsions among the positive charges on the protonated cyclic polyamines. This grouping phenomenon is, as expected, much more marked for smaller macrocycles. For large azamacrocycles, the charges that accumulate in the macrocyclic framework as the degree of protonation increases experience smaller repulsions than in the case of the smaller macrocycles (refs. 21-25). The polybasic nature and the cyclic architecture enable large polyazacycloalkanes to form many highly, positively charged (protonated) species in the neutral pH region. As an example in Fig. 3b the distribution diagram for the system $\mathrm{H}^{+} / \mathrm{L} 10$ has been reported. These species, strongly interacting with anions, are used for anion coordination studies (refs. 26-28). Another intriguing feature of large polyazacycloalkanes is their ability to form polynuclear metal complexes. In Table 2 the formation constants of the species formed between copper(II) and large polyazacycloalkanes have been listed. With the only exception of the smallest macrocycle of the series, L7, which forms also a mononuclear complex $|\mathrm{CuL} 7|^{2+}$ (ref, 22) all the other macrocycles form polynuclear copper(II) complexes. In particular (see Table 2) the largest macrocycles LII and LI2 form both binuclear and trinuclear species (ref. 25). The stability of the binuclear $\mid \mathrm{Cu}_{2} \mathrm{~L}^{4+}$ species is invariably high, demonstrating the tendency of this macrocyclic series to bind more than 
TABLE 1. Basicity constants for the $|3 \cdot k|$ aneN series $(k=7-12)$ in aqueous solution at $25^{\circ} \mathrm{C}$. (L7, L8 I=0.5 mol dm $\mathrm{km}^{-3} ;$ L9-L12 I=0.15 mol dm $\mathrm{dm}^{-3}$ )

LogK

\begin{tabular}{|c|c|c|c|c|c|c|}
\hline Reaction & $\mathrm{L}=\mathrm{L} 7$ & $\mathrm{~L}=\mathrm{L} 8$ & $L=L 9$ & $\mathrm{~L}=\mathrm{L} .10$ & $\mathrm{~L}=\mathrm{L} 11$ & $\mathrm{~L}=\mathrm{L} 12$ \\
\hline $\mathrm{H}^{\mathrm{a}}+\mathrm{L}=\mathrm{HL}$ & 9.83 & 10.01 & 9.59 & 9.85 & 9.82 & 9.86 \\
\hline $\mathrm{H}+\mathrm{L}=\mathrm{H}_{2} \mathrm{~L}$ & 9.53 & 9.50 & 9.40 & 9.44 & 9.45 & 9.60 \\
\hline $\mathrm{H}+\mathrm{H}_{2} \mathrm{~L}=\mathrm{H}_{3} \mathrm{~L}$ & 8.84 & 9.10 & 8.77 & 8.95 & 9.01 & 8.92 \\
\hline $\mathrm{H}+\mathrm{H}_{3} \mathrm{~L}=\mathrm{H}_{4} \mathrm{I}$ & 6.72 & 8.29 & 8.27 & 8.56 & 8.62 & 8.94 \\
\hline $\mathrm{H}+\mathrm{H}_{4} \mathrm{~L}=\mathrm{H}_{5} \mathrm{I}$ & 4.04 & 5.01 & 6.37 & 7.79 & 8.08 & 8.13 \\
\hline$H+H_{5} L=H_{6} L$ & 2.43 & 3.71 & 4.22 & 5.24 & 6.47 & 7.80 \\
\hline $\mathrm{H}+\mathrm{H}_{6} \mathrm{~L}=\mathrm{H}_{7} \mathrm{~L}$ & 2.30 & 2.98 & 3.24 & 3.84 & 4.52 & 5.60 \\
\hline $\mathrm{H}+\mathrm{H}_{7} \mathrm{~L}=\mathrm{H}_{8} \mathrm{~L}$ & -- & 1.97 & 2.31 & 3.02 & 3.57 & 4.25 \\
\hline $\mathrm{H}+\mathrm{H}_{8} \mathrm{~L}=\mathrm{H}_{9} \mathrm{~L}$ & -- & -- & 1.8 & 1.97 & 2.76 & 3.52 \\
\hline$H+H_{9} L=H_{10}$ & -- & -- & -- & 1.8 & 2.23 & 2.65 \\
\hline $\mathrm{H}+\mathrm{H}_{10} \mathrm{~L}=\mathrm{H}_{11} \mathrm{~L}$ & -- & -- & -- & -- & 1.7 & 2.3 \\
\hline $\mathrm{H}+\mathrm{H}_{11} \mathrm{~L}=\mathrm{H}_{12} \mathrm{~L}$ & -- & - & -- & -- & -- & $1.0^{\mathrm{b}}$ \\
\hline
\end{tabular}
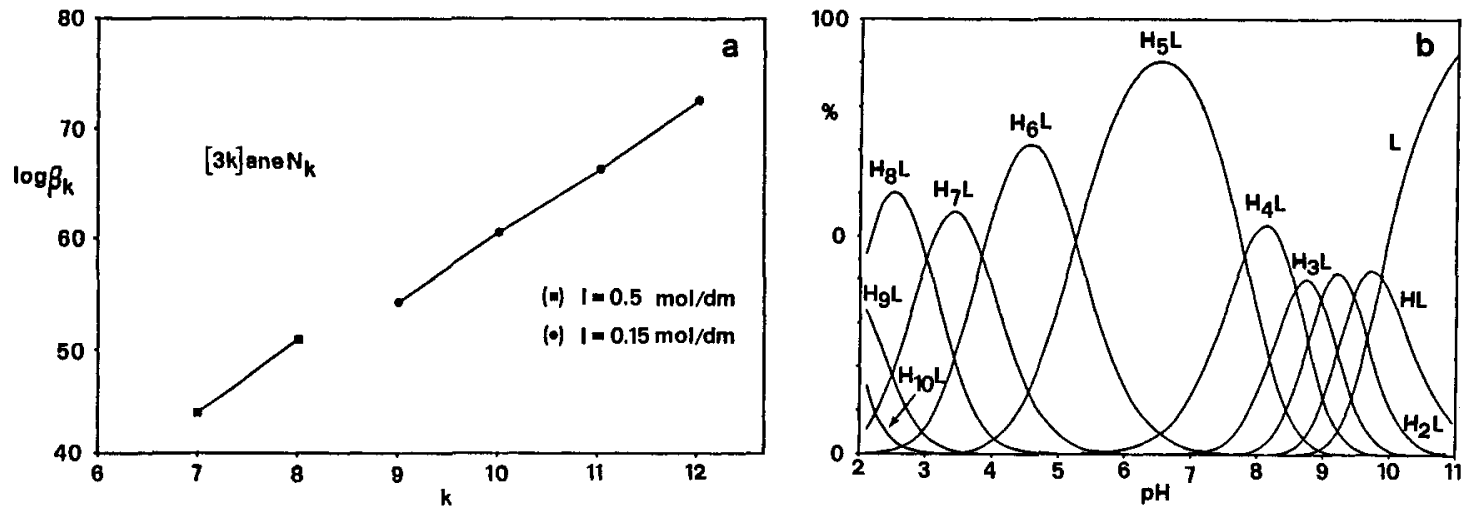

Fig. 3. a) Overall basicity constants for the $|3 \cdot \mathrm{k}|$ aneN $\mathrm{N}_{\mathrm{k}}$ series.

b) Distribution diagram for the system $\mathrm{H}^{+} / \mathrm{L} 10$ (charges omitted).

one metal ion for each ligand molecule. The enthalpy of formation of the binuclear species $\left|\mathrm{Cu}_{2} \mathrm{~L}\right|^{4+}$ has been determined by direct microcalorimetry for $\mathrm{L}=\mathrm{L} 8$, $\Delta \mathrm{H}^{\circ}=-39.0 \mathrm{kcal} \mathrm{mol}^{-1}$ (ref. 21); $\mathrm{L}=\mathrm{L} 9, \Delta \mathrm{H}^{\circ}=-42.8 \mathrm{kcal}$ mol ${ }^{-1}$ ( $\mathrm{ref} .23$ ); $\mathrm{L}=\mathrm{L} 10, \Delta \mathrm{H}^{\circ}=-45.5$ $\mathrm{kcal} \mathrm{mol}^{-1}$ (ref. 24). These values demonstrate that the formation of these complexes is strongly exothermic and indicate a trend for the formation reaction enthalpies of the binuclear species, which are more exothermic as the overall size of the macrocycle increases. Two main effects can be invoked to explain this trend: i) increase in the number of donor atoms involved in the coordination to the metal ions; ii) increase in ligand flexibility and decrease of the electrostatic repulsions between the metal ions coordinated to the larger macrocycles. A trend similar to that of the formation enthalpies is found for the stability constants. The binuclear species $\left|\mathrm{Cu}_{2} \mathrm{~L}\right|^{4+}$ become more stable as the size of the macrocycle increases. The only exception is provide by the values of the equilibrium formation constant of $|\mathrm{Cu} \mathrm{L}|^{4+}$ which are slightly larger than those of $\left|\mathrm{Cu}_{2} \mathrm{L9}\right|^{4+}$. This result can be explained taking into account that the equilibrium constants for the copper(II)/L8 system have been determined at higher ionic strength $\left(0.5 \mathrm{~mol}^{2} \mathrm{dm}^{-3}\right)$ than those of all other systems $\left(0.15 \mathrm{~mol} \mathrm{dm}{ }^{-3}\right)$. Such experimental evidence allow us to conclude that for the four macrocycles L7, L8, L9, and L10 all of the nitrogen donor atoms 
TABLE 2. Logarithms of the formation constants of copper(II) complexes of large polyazacycloalkanes in aqueous solution at $25^{\circ} \mathrm{C}$.

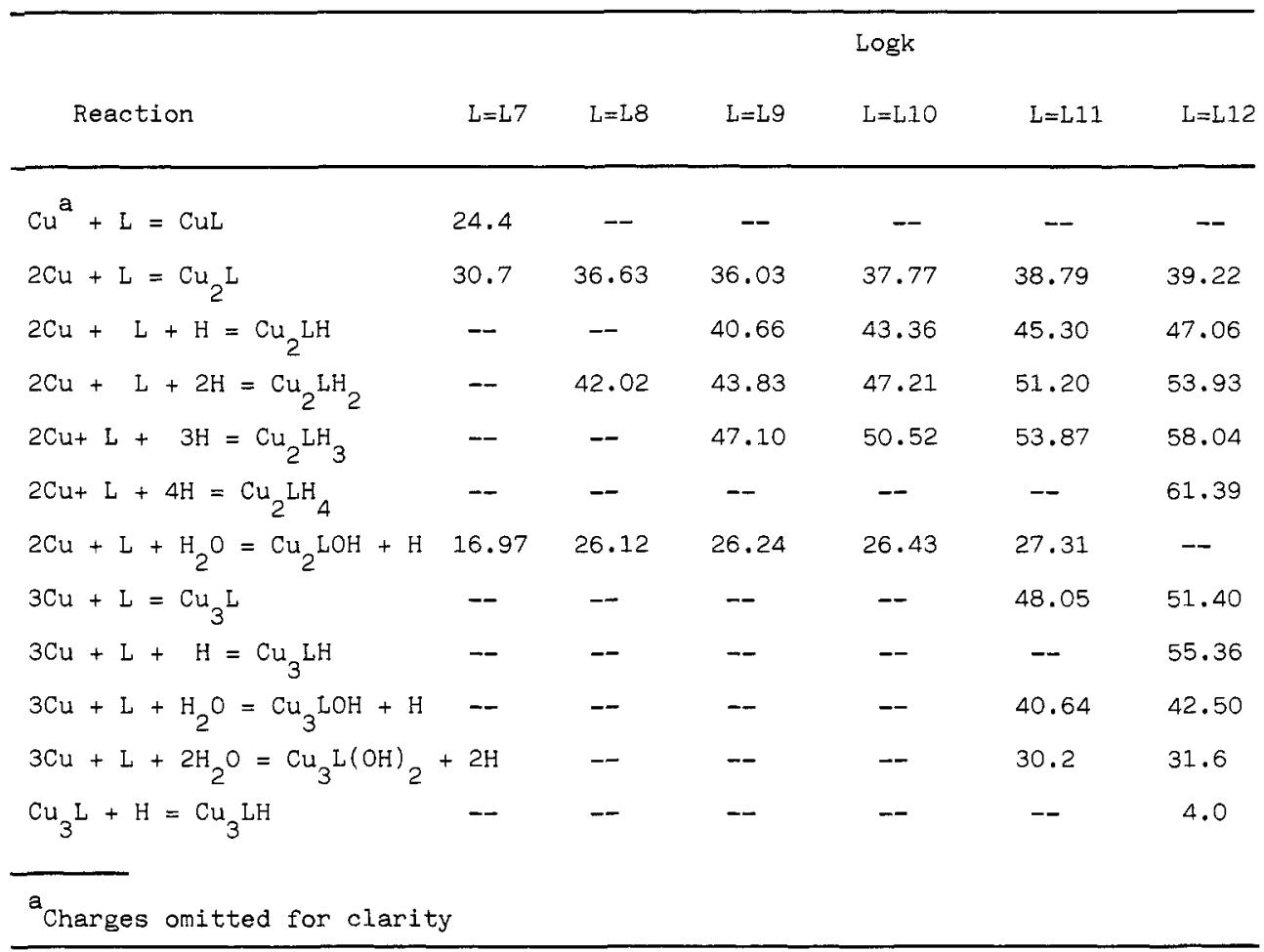

in the macrocycle are involved in the formation of the binuclear species. The electronjc spectra of this species show a typical, wide, absorption band between $16200-16500 \mathrm{~cm}^{-1}$, with molar absorption ranging from 220-280 per copper(II) ion. With $L=11$ and $L=12$ stable trinuclear species $\left|\mathrm{Cu}_{3} \mathrm{~L}\right|^{\mathrm{C}+}$ are formed (see Table 2). The high stability of $\left|\mathrm{Cu}_{3} \mathrm{LI2}\right|^{6+}$ and the small equilibrium constant relative to the addition of one hydrogen ion indicate that all twelve donor atoms are involved in the formation of this species (ref. 25).

Due to the abundance of donor atoms present in these large macrocycles many protonated species are present at each equilibrium. As expected the larger macrocycles $\mathrm{L} 11$ and $\mathrm{L} 12$ form more protonated species than the other macrocycles of the series. Polynuclear hydroxo complexes are other interesting species formed by all macrocycles of the series. It is worth noting that in the formation equilibria of mononuclear complexes between copper(II) ion and polyazacycloalkanes the formation of hydroxo species is rare (refs. 14,19). In our case, instead, the hydroxo species are numerous and are all very stable. In the case of $\left|\mathrm{Cu}_{2}(\mathrm{~L} 8) \mathrm{OH}\right|^{3+}$ it has been demonstrated that the magnetic susceptibility, measured in solution by the Evans method, lowers significantly on increasing the $\mathrm{pH}$ and the hydroxo species concentration (ref. 21). This experimental evidence supports the hypothesis that this species has the hydroxide ion bridging the two copper(II) ions with the consequent increasing of the metal-metal interactions.

Cyclic voltammetric studies carried out on aqueous solutions of $\left|\mathrm{Cu} \mathrm{L}_{2}\right|^{4+}$ and $\left|\mathrm{Cu} \mathrm{L}_{2} \mathrm{~L}\right|^{4+}$ complexes (refs. 21-22) show a current/potential profile with two consecutive peaks in reduction, followed, in the reverse scan, by two oxidation peaks (see Fig. 4). These results indicate that both complexes undergo reversible reductions into the binuclear copper(I) species by two independent monoelectronic steps. The reduced species are unstable with respect to the demetalation and reduction to metal.

Recent equilibrium studies have demonstrated that also zinc(II) forms binuclear complexes with L9, L10 and L11 (ref. 29). In Table 3 the logarithms of the formation constants of polynuclear zinc(II) complexes with the latter macrocycles have been reported.

Although zinc(II) rarely forms binuclear complexes in aqueous media with synthetic ligands the large macrocycles so far investigated L9, L10 and LII form stable binuclear zinc complexes. An X-ray investigation still in progress has shown the presence of binuclear zinc(II) cations in crystals of $\mathrm{Zn}_{2} \mathrm{LIOSCN}\left(\mathrm{ClO}_{4}\right)_{3}$ ( $r$ ef. 28). No mononuclear species are formed and the high stability of the $\left|\mathrm{Zn} \mathrm{n}_{2}\right|^{4+}$ species indicate a strong overall interaction between the two zinc(II) ions and the nitrogen donor atoms. 


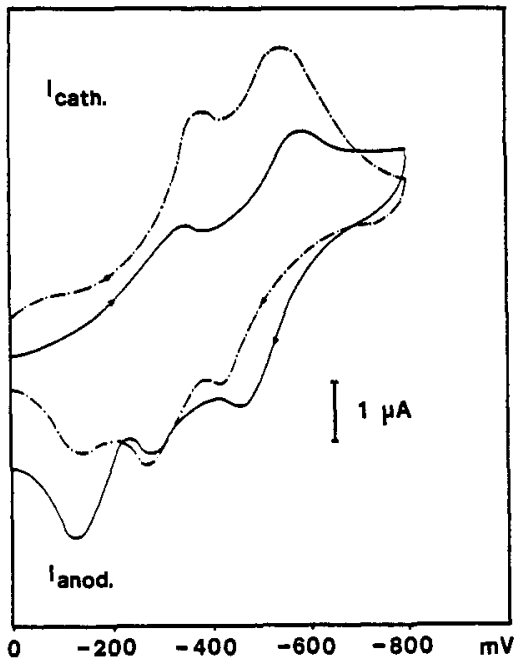

TABLE 3. Logarithms of the formation constants of zinc(II) complexes of L9, LIO and L1I in aqueous solution at $25{ }^{\circ} \mathrm{C}$.

\begin{tabular}{lccc}
\hline & Logk & \\
Reaction & $\mathrm{L}=\mathrm{L9} 9$ & $\mathrm{~L}=\mathrm{L} 10$ & $\mathrm{~L}=\mathrm{L} 11$ \\
\hline $2 \mathrm{Zn}+\mathrm{L}=\mathrm{Zn}_{2} \mathrm{~L}$ & 20.51 & 22.47 & 23.92 \\
$2 \mathrm{Zn}+\mathrm{L}+\mathrm{H}=\mathrm{Zn}_{2} \mathrm{LH}$ & 26.93 & -- & -- \\
$2 \mathrm{Zn}+\mathrm{L}+2 \mathrm{H}=\mathrm{Zn}_{2} \mathrm{LH}_{2}$ & 32.78 & 35.20 & 36.62 \\
$2 \mathrm{Zn}+\mathrm{L}+3 \mathrm{H}=\mathrm{Zn}_{2} \mathrm{LH}_{3}$ & -- & 40.41 & 42.17 \\
$2 \mathrm{Zn}+\mathrm{L}+\mathrm{H}_{2} \mathrm{O}=\mathrm{Zn}_{2} \mathrm{LOH}+\mathrm{H}$ & 13.45 & 14.03 & 15.40 \\
\hline Charges omitted for clarity. & & \\
\hline
\end{tabular}

Fig. 4. Cyclic voltammetry curves on aqueous solution $\left(10^{-4} \mathrm{~mol} \mathrm{dm}^{-3}\right)$ containing $\left\{\mathrm{Cu}_{2} \mathrm{~L} 7\right\}^{4+}(-)$ and $\left|\mathrm{Cu}_{2} \mathrm{~L} 8\right|^{4+}(\ldots)$

\section{STRUCTURAL ASPECTS}

Among the $|3 \cdot \mathrm{k}|$ aneN $\mathrm{N}_{\mathrm{k}}$ series and in spite of the great efforts in order to obtain crystals of polynuclear copper(II) complexes suitable for X-ray analysis, only in the case of L8 and L10 the isolation of good crystals was possible. In Fig. 5 and Fig. 6 the structures of the cations in $\left|\mathrm{Cu}_{2}(\mathrm{L8}) \mathrm{Cl}_{2}\right|\left(\mathrm{ClO}_{4}\right)_{2}$ and in $\left|\mathrm{Cu}_{2}(\mathrm{LIO}) \mathrm{HCl}_{2}\right|\left(\mathrm{ClO}_{4}\right)_{3} \cdot 4 \mathrm{H}_{2} \mathrm{O}$ are shown.

The crystal structure of $\left|\mathrm{Cu}_{2}(\mathrm{~L} 8) \mathrm{Cl}_{2}\right|\left(\mathrm{ClO}_{4}\right)_{2}$ (ref. 21) consists of centrosymmetric $\mathrm{Cu}_{2} \mathrm{L8}$ units, connected by $\mathrm{Cu}-\mathrm{Cl}^{2}-\mathrm{Cu} \cdot \mathrm{C} \mathrm{Cl}_{1} \cdot \mathrm{cu} \mathrm{c}^{2}$ chains running along the $\mathrm{b}$ axis. Each copper atom is coordinated by four nitrogen atoms of the macrocycle and one chloride ion, forming a distorted square pyramid (see Fig. 5).

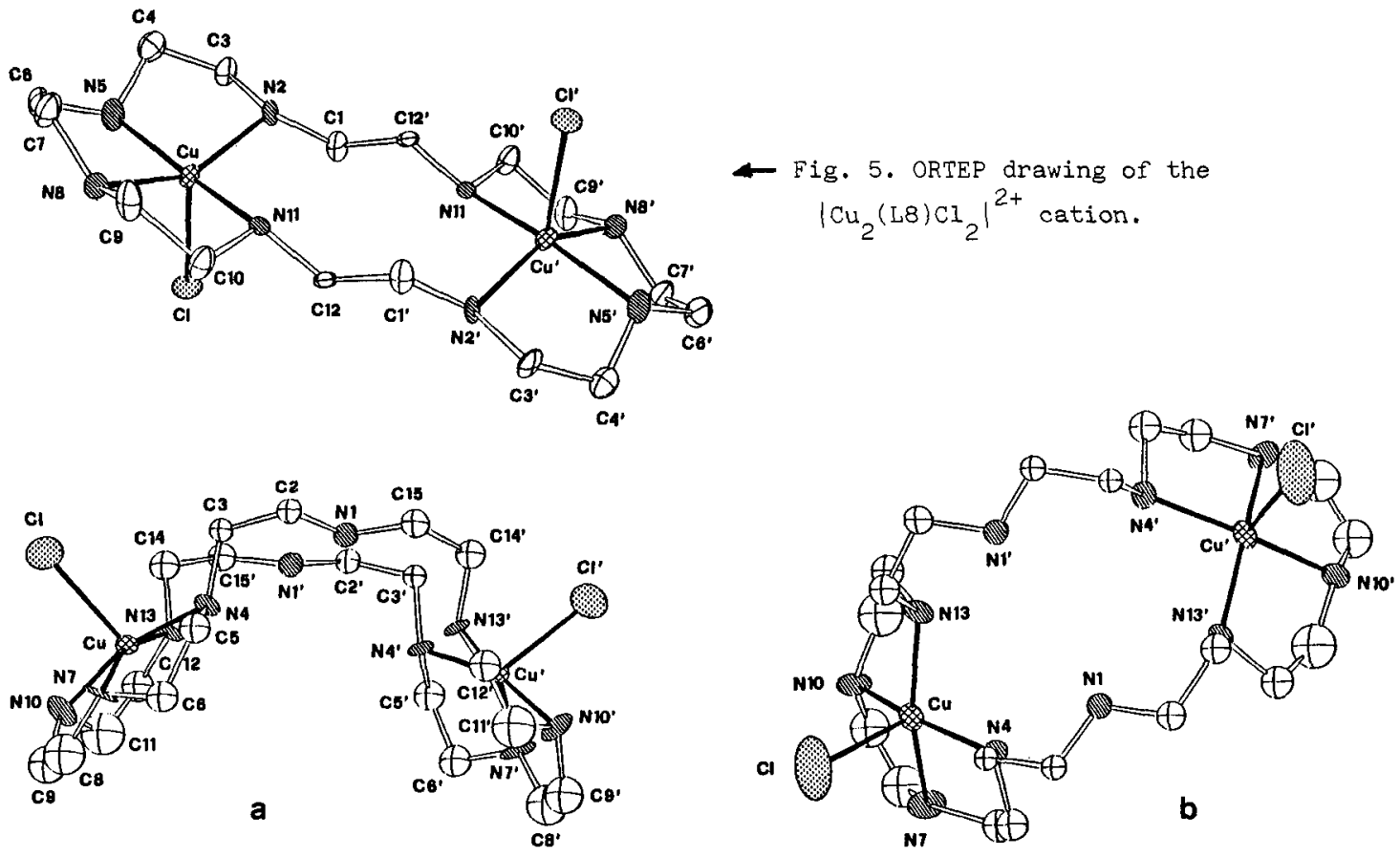

Fig. 6. a) ORTEP drawing of the $\left|\mathrm{Cu}_{2}(\mathrm{~L} 10) \mathrm{HCl}_{2}\right|^{3+}$ cation. b) Top view of the same cation. 
The nitrogen atoms lie approximately in the basal plane with the copper atom $0.36 \AA$ out of the plane. The intramolecular copper-copper distance is $6.138 \AA$. The ring has a chair-shaped configuration, with all five-membered chelate rings in the gauche configuration. The structure of the compound $\left|\mathrm{Cu}_{2}(\mathrm{~L} 10) \mathrm{HCl}_{2}\right|\left(\mathrm{ClO}_{4}\right)_{3} \cdot 4 \mathrm{H}_{2} \mathrm{O}$ (ref. 24) consists of binuclear $\left|\mathrm{Cu}_{2}(\mathrm{~L} 10) \mathrm{HCl}_{2}\right|^{3+}$ cations, disordered perchlorate anions, and water molecules bridging the complex cations in the crystal lattice by hydrogen bonds. In the binuclear unit each copper atom is coordinated by four nitrogen atoms of the macrocyclic ligand and by one chloride ion forming a slightly distorted square pyramid (see Fig. 6 a). One of the two uncoordinated nitrogen atoms is protonated. The site of protonation must be on $\mathrm{N}(1)$ or $\mathrm{N}\left(I^{\prime}\right)$ but since these are crystallographically equivalent due to the presence of the twofold axis, the proton is statistically distributed between them. The distance of $3.90 \AA$ between $\mathrm{N}(1)$ and $\mathrm{N}\left(1^{\prime}\right)$ (Fig. 5) rules out any possibility of bridging for the hydrogen atom. The nitrogen atoms lie in the basal plane with the copper atom $0.34 \AA$ out of the plane. The mean $\mathrm{Cu}-\mathrm{N}$ distance of $2.03 \AA$ is identical (within experimental error) to the analogous distance in the $\left|\mathrm{Cu}_{2}(\mathrm{~L} 8) \mathrm{Cl}_{2}\right|\left(\mathrm{ClO}_{4}\right)_{2}$ complex. The intramolecular $\mathrm{Cu}-\mathrm{Cu}$ distance is $7.26 \AA$ compared to the $6.138 \AA$ distance found in $\left|\mathrm{Cu}_{2}(\mathrm{~L} 8) \mathrm{Cl}_{2}\right|\left(\mathrm{ClO}_{4}\right)_{2}$. The macrocycle has a saddle-shaped configuration, the two least squares planes through the coordinating nitrogens form an angle of $83.8^{\circ}$. As in the $\left|\mathrm{Cu}_{2}(\mathrm{~L} 8) \mathrm{Cl}_{2}\right|\left(\mathrm{ClO}_{4}\right)_{2}$ compound all the five membered chelate rings are in the gauche configuration. Crystal structures of protonated macrocyclic complexes are rare because protonated species are present as a small fraction and in a narrow pH-range in the solution equilibria. In spite of the above considerations a protonated complex species $\left|\mathrm{Cu}_{2}(\mathrm{LlO}) \mathrm{H}\right| \mathrm{Cl}_{2}\left(\mathrm{ClO}_{4}\right)_{3} \cdot 4 \mathrm{H}_{2} \mathrm{O}$ was obtained in crystalline form. The occurrence of such monoprotonated species in the solid state can be attributed to various stabilizing effects such as chloride coordination and hydrogen bonding network.

\section{ANION COORDINATION}

Because of the many basic centres, large polyazamacrocycles are able to form polyprotonated, highly charged, species in the neutral pH region. The cyclic nature of these compounds further concentrates the positive charge, making these species strongly interacting with anions. The anions we have so far investigated, hexacyanoferrate(II) and hexacyanocobaltate(III) (refs. 26-28), are complexes. The binding of these metal complexes by highly charged macrocycles has led to the coinage of the expression 'supercomplexes'. The systems anionic species/protonated macrocycle have been studied by potentionetry. In the case of hexacyanoferrate(II) the cyclic voltammetry was also used to obtain electrochemical independent results, comparable with those obtained from potentiometry. In Table 3 the species formed and the relative formation constants are listed. Many species are formed, all with 1:1 stoichiometry. In order to form a 'supercomplexed' species, the macrocycle has to be at least tetracharged (see Table 4). For the same macrocycle the stability of the supercomplex increases as the macrocycle becomes more protonated (charged). Furthermore the $\mathrm{E}^{1} / 2$ for the couple $\left|\mathrm{Fe}(\mathrm{CN}){ }_{6}\right|^{3-} /\left|\mathrm{Fe}(\mathrm{CN}){ }_{6}\right|^{4-}$ in the complexed species increases step by step (Fig. 7) as the charge increases. These results have been interpreted by assuming that the most important role in supercomplex formation is played by the coulombic forces, though other effects, such as hydrogen bonding and macrocycle configuration should be important and may give significant contributions to the overall stability of the supercomplexed species. Another important observation which can be made is the absence of any selectivity.

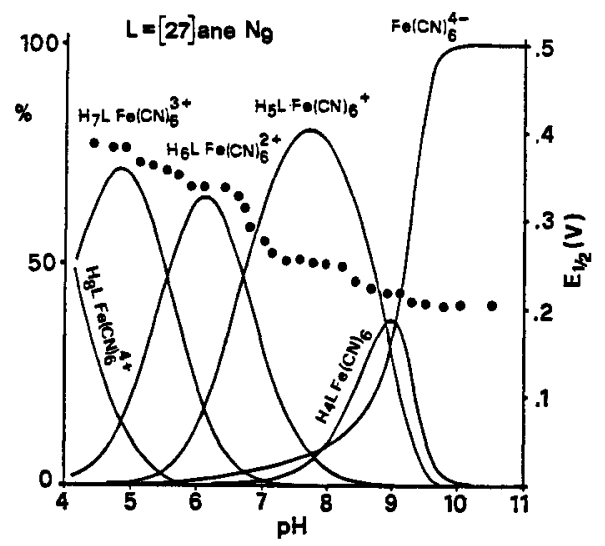

Fig. 7. Distribution diagram $(-)$ for the system $\mathrm{H}^{+} / \mathrm{L} 9 /\left|\mathrm{Fe}(\mathrm{CN}){ }_{6}\right|^{4-}$ and $\mathrm{E}^{1 / 2}(\bullet)$ for the couple $\left.\left(\mathrm{H}_{\mathrm{n}} \mathrm{L} 9\right)\left|\mathrm{Fe}(\mathrm{CN}){ }_{6}\right|^{(\mathrm{n}-4)+/\left(\mathrm{H}_{\mathrm{n}} \mathrm{Lg}\right) \mid \mathrm{Fe}(\mathrm{CN})}{ }_{6}\right|^{(\mathrm{n}-3)+}$ vs. $\mathrm{pH}$. 
Recently we have measured ( $\mathrm{ref}, 30$ ) the thermodynamic parameter $\Delta \mathrm{G}^{\circ}, \Delta \mathrm{H}^{\circ}$ and $\mathrm{T} \Delta \mathrm{S}^{\circ}$ for the supercomplex formation reactions between $\left|\mathrm{Fe}(\mathrm{CN}){ }_{6}\right|^{4-},\left|\mathrm{Co}(\mathrm{CN}){ }_{6}\right|^{3-}$ and the tetra-protonated tetraaza macrocycle 1,6,11,16-tetraazacycloeicosane. These results indicate that the overall stability of the supercomplexed species is due both to favorable enthalpic and entropic terms.

Assuming that the anion complexing unit of these macrocycles consists of several positively charged binding sites arranged around the cavity defined by the molecular shape, a good question could be whether the anionic species goes inside the macrocyclic cavity or not. For the large macrocycle L10 the crystal structure of the supercomplex $\mathrm{H}_{8} \mathrm{~L} 1 \mathrm{O} /\left.\mathrm{Co}(\mathrm{CN})_{6}\right|_{2} \mathrm{Cl}_{2} \cdot 1 \mathrm{OH}_{2} \mathrm{O}$ was resolved by X-ray analysis (ref. 27) (see Fig. 8).

TABLE 4. Logarithms of the equilibrium constants for 'supercomplex' formation between the large macrocycles and the anions $\left.\left|\mathrm{Fe}(\mathrm{CN}){ }_{6}^{4-}\right| \mathrm{Co}(\mathrm{CN})\right|_{6} ^{3-}$ in aqueous solution at $25^{\circ} \mathrm{C}$.

\begin{tabular}{|c|c|c|c|c|}
\hline \multirow[b]{2}{*}{ Reaction } & \multicolumn{4}{|c|}{ Logk } \\
\hline & $\mathrm{L}=\mathrm{L} 7$ & $\mathrm{~L}=\mathrm{L} 9$ & $\mathrm{~L}=\mathrm{L} .10$ & $\mathrm{~L}=\mathrm{L} .1 .1$ \\
\hline $\mathrm{H}_{4} \mathrm{~L}^{4+}+\left|\mathrm{Fe}(\mathrm{CN})_{6}\right|^{4-}=\left|\mathrm{H}_{4} \mathrm{LFe}(\mathrm{CN})_{6}\right|$ & 4.27 & 4.06 & 3.69 & 3.6 .1 \\
\hline $\mathrm{H}_{5} \mathrm{~L}^{5+}+\left|\mathrm{Fe}(\mathrm{CN}){ }_{6}\right|^{4-}=\left|\mathrm{H}_{5} \mathrm{LFe}(\mathrm{CN}){ }_{6}\right|^{+}$ & 5.42 & 5.63 & 4.78 & 4.66 \\
\hline $\mathrm{H}_{6} \mathrm{~L}^{6+}+\left|\mathrm{Fe}(\mathrm{CN}){ }_{6}\right|^{4-}=\left|\mathrm{Hi}_{6} \mathrm{LFe}(\mathrm{CN}){ }_{6}\right|_{3+}^{2+}$ & -- & 7.60 & 6.23 & 5.72 \\
\hline $\mathrm{H}_{7}{ }^{1+}+\left|\mathrm{Fe}(\mathrm{CN})_{6}\right|^{4-}=\left|\mathrm{H}_{7} \mathrm{LFe}(\mathrm{CN})_{6}\right|^{3+}$ & -- & 9.33 & 7.92 & 6.93 \\
\hline $\mathrm{H}_{8} \mathrm{~L}^{8+}+\left|\mathrm{Fe}(\mathrm{CN}){ }_{6}\right|^{4-}=\left|\mathrm{H}_{8} \mathrm{LFe}(\mathrm{CN}){ }_{6}\right|^{4+}$ & -- & -- & 9.03 & 8.07 \\
\hline $\mathrm{H}_{4} \mathrm{~L}^{4+}+\left|\mathrm{CO}(\mathrm{CN})_{6}\right|^{3-}=\left|\mathrm{H}_{4} \mathrm{LCO}(\mathrm{CN})_{6}\right|^{+}$ & - & 2.61 & 2.02 & 2.63 \\
\hline $\mathrm{H}_{5} \mathrm{~L}^{5+}+\left|\mathrm{CO}(\mathrm{CN})_{6}\right|^{3-}=\left|\mathrm{H}_{5} \mathrm{LCO}(\mathrm{CN})_{6}\right|^{2+}$ & -- & 3.00 & 2.09 & 3.05 \\
\hline $\mathrm{H}_{6} \mathrm{~L}^{6+}+\left|\mathrm{CO}(\mathrm{CN})_{6}\right|^{3-}=\left|\mathrm{H}_{6} \mathrm{LCO}(\mathrm{CN})_{6}\right|^{3+}$ & - & 3.36 & 2.35 & 3.52 \\
\hline $\mathrm{H}_{7} \mathrm{~L}^{\mathrm{l}+}+\left|\mathrm{Co}(\mathrm{CN}){ }_{6}\right|^{3-}=\left|\mathrm{H}_{7} \mathrm{LCo}(\mathrm{CN})_{6}\right|^{4+}$ & -- & 3.78 & 3.23 & 4.05 \\
\hline $\mathrm{H}_{8} \mathrm{~L}_{9+}^{8+}+\left|\mathrm{Co}(\mathrm{CN}){ }_{6}\right|_{3-}^{3-}=\left|\mathrm{H}_{8} \mathrm{LCO}(\mathrm{CN}){ }_{6}\right|_{6+}^{5+}$ & -- & 4.09 & 3.66 & 4.56 \\
\hline $\mathrm{H}_{9} \mathrm{~L}^{\mathrm{yt}}+\left|\mathrm{Co}(\mathrm{CN})_{6}\right|^{3-}=\left|\mathrm{H}_{9} \mathrm{LCO}(\mathrm{CN})_{6}\right|^{0+}$ & -- & - & 4.43 & 4.85 \\
\hline $\mathrm{H}_{10}{ }^{\mathrm{LLt}}+\left|\mathrm{Co}(\mathrm{CN}){ }_{6}\right|^{\mathrm{SO}}=\left|\mathrm{H}_{10}{ }^{\mathrm{LCO}(\mathrm{CN})}{ }_{6}\right|^{1+}$ & -- & -- & -- & 5.35 \\
\hline
\end{tabular}

(A)

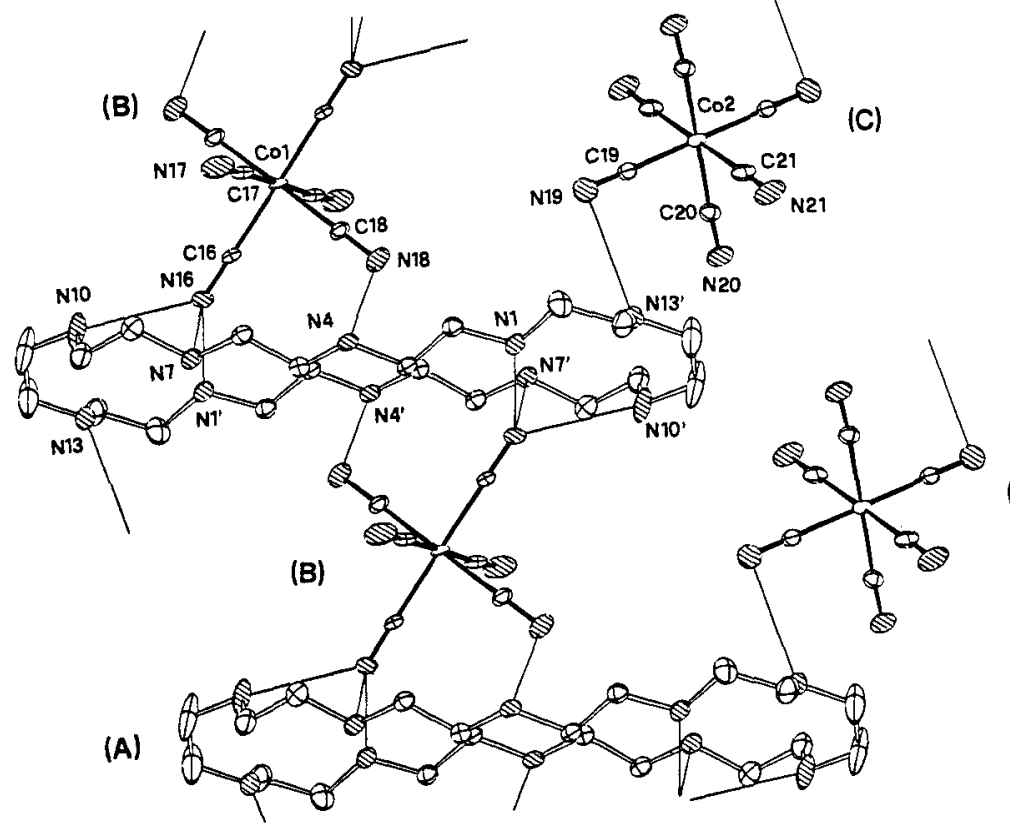

(c)

Fig. 8. ORTEP view of a part of crystal packing showing the L10 ring (A) and hexacyanocobaltate(III) anions(B) and (C) together with the hydrogen bonds among them. 
The structure consists of $\left|\mathrm{H}_{8} \mathrm{LlO}\right|^{8+}$ cations, $\left|\mathrm{Co}(\mathrm{CN})_{6}\right|^{3-}$, chloride anions and water molecules. The protonated macrocyclic ring shows an elongated elliptical shape. Its conformation is imposed by the strong electrostatic repulsions between positively charged nitrogen atoms. The crystal structure of this supercomplex proves that the anionic species does not go inside the cavity; the rigid conformation is determined by electrostatic repulsions and very likely maintained in solution; coulombic interactions and hydrogen bonds between cationic and anionic species contribute very much to the stability of the supercomplexed species.

Acknowledgement We are indebted to our colleagues E. Garcia-España, S. Mangani and $P$. Orioli for their contributions, well documented in this article.

\section{REFERENCES}

1. J.J. Christensen, D.J. Eatough, R.M. Izatt, J.M. Lehn, P.Ch. Meier, W.E. Morf, W. Simon and M.R. Truter, Structure and Bonding, 16, (1973).

2. J.J. Christensen, and R.M. Izatt, Synthetic Multidentate Macrocyclic Compounds, Academic Press, New York (1978).

3. G.A. Melson, Coordination Chemistry of Macrocyclic Compounds, Plenum Press, New York, (1979).

4. M. Hiraoka, Crown Compounds, Their Characteristic and Applications, Elsevier, Amsterdam (1982).

5. B. Bosnich, C.K. Poon and M.L. Tobe, Inorg. Chem., 8, 1102 (1965).

6. D.K. Cabbiness and D.W. Margerum, J. Am. Chem. Soc., 91, 6540 (1969).

7. F.P. Hinz and D.W. Margerum, Inorg. Chem., 13, 2941 (1974).

8. M. Kodama and E. Kimura, J. Chem. Soc., Chem. Commun., 326 (1975).

9. M. Kodama and E. Kimura, J. Chem. Soc., Dalton Trans., 116 (1976).

10. A. Anichini, R.M. Clay, L. Fabbrizzi and P. Paoletti, J. Chem. Soc., Chem. Commun., 244 (1977).

11. A.P. Leugger, L. Hertli and T.A. Kaden, Helv. Chim. Acta, 61, 2297 (1978).

12. M. Micheloni, A. Sabatini and P. Paoletti, J. Chem. Soc., Perkin Trans., 2, 828 (1978).

13. R.M. Clay, M. Micheloni, P. Paoletti and W.V. Steele, J. Am. Chem. Soc., 101, 4119 (1979).

14. A. Bianchi, L. Bologni, P. Dapporto, M. Micheloni and P. Paoletti, Inorg. Chem., 23, 1201 (1984).

15. T.J. Atkins, J.E. Richman and W.F. Dettle, Org. Synth., 58, 86 (1978).

16. B. Dietrich, M. Hosseini, J.M. Lehn and R.B. Sessions, Helv. Chim. Acta, 66,1262 (1983).

17. B. Dietrich, M. Hosseini, J.M. Lehn and R.B. Sessions, J. Am. Chem. Soc., 103, 1282 (1981).

18. E. Kimura and A. Sakonaka, J. Am. Chem. Soc., 104, 4984 (1982).

19. E. Gallori, E. Martini, M. Micheloni, and P. Paoletti, J. Chem. Soc., Dalton Trans., $1722(1980)$.

20. M. Bartolini, A. Bianchi, M. Micheloni and P. Paoletti, J. Chem. Soc., Perkin Trans. 2, 1345 (1982).

21. A. Bianchi, S. Mangani, M. Micheloni, V. Nanini, P. Orioli, P. Paoletti and B. Seghi, Inorg. Chem., 24, 1182 (1985).

22. A. Bianchi, M. Micheloni and P. Paoletti, Inorg. Chem., 24, 3702, (1985).

23. A. Bencini, A. Bianchi, E. Garcia-España, M. Giusti, M. Micheloni and P. Paoletti, Inorg. Chem., 26, 681 (1987).

24. A. Bencini, A. Bianchi, E. Garcia-España, M. Giusti, S. Mangani, M. Micheloni, P. orioli and P. Paoletti, Inorg. Chem., 26, 000 (1987).

25. A. Bencini, A. Bianchi, E. Garcia-España, M. Micheloni and P. Paoletti, Inorg. Chem., submitted.

26. A. Bianchi, E. Garcia-España, M. Micheloni and P. Paoletti, Inorg. Chim. Acta, 102, L9 (1985).

27. A. Bianchi, E. Garcia-España, S. Mangani, M. Micheloni, P. Orioli and P. Paoletti, J. Chem. Soc., Chem. Commun,, 000 (1987).

28. A. Bencini, A. Bianchi, E. Garcia-España, M. Giusti, S. Mangani, M. Micheloni, P. Orioli and P. Paoletti, Inorg. Chem., submitted.

29. A. Bianchi, E. Garcia-España, S. Mangani, M. Micheloni, P. Orioli and P. Paoletti, to be published.

30. A. Bianchi, M. Micheloni, P. Paoletti, to be published. 